\title{
Abnormal Proximal Axons of Clarke's Neurons In Sporadic Motor Neuron Disease
}

\author{
P. AVERBACK and P. CROCKER
}

SUMMARY: Filamentous axonal masses, similar to the abnormal enlargements found in the ventral horns, were found in Clarke's nucleus in six cases of sporadic A LS. Clarke's nucleus is generally thought to be normal in sporadic $A L S$, but the present findings, in conjunction with distal spinocerebellar degeneration which is often described, suggest that this system is also pathologically involved.

RESUME: Des masses axonales filamenteuses, semblables aux élargissements anormaux trouvés dans les cornes antérieures. furent trouvées dans le noyau de Clarke chez six cas de SLA sporadique. Le noyau de Clarke est généralement considéré comme normal dans la SLA sporadique, mais les résultats présents, en plus de la dégénérescence spinocérébelleuse distale souvent décrite, suggèrent que ce système peut aussi être impliqué dans la pathologie.

From the Department of Pathology, University of Cambridge, Cambridge. England.

Reprint requests to: Dr. P. Averback. Department of Pathology, 3775 University Street, Montreal, PQ, H3A 2B4. Canada.

\section{INTRODUCTION}

Clarke's columns (nucleus dorsalis) are generally considered to be normal in sporadic motor neuron disease (ALS). Distal spinocerebellar tract degeneration has been known since the turn of the century (Holmes, 1909), but abnormalities in the thoracic nucleus have not been found. This report describes axonal enlargements comparable to those described in anterior horn cells, which have been found in Clarke's columns in six cases of sporadic ALS.

\section{MATERIALS AND METHODS}

Patients are summarized in Table 1 . Cases were selected consecutively as available. Spinal cords were initially fixed in formalin in five of the cases. Samples of Clarke's columns were dissected out and post-fixed in 1\% glutaraldehyde, embedded in Spurr resin and thin sectioned. Sections were mounted on copper grids, stained with uranyl acetate and lead citrate and examined in a Philips 300 electron microscope. Bodian stained paraffin sections from several levels of the nucleus were subsequently examined in order to make some estimate of frequency of the changes described.

\section{RESULTS}

Most striking were the abnormally enlarged axons which were found in each case. Some of these were nearly as large as neuronal perikarya (Figure 1). The bulbous enlargements consisted of neurofilaments coursing in many directions, with a tapering end to the sectioned axon usually apparent. Continuity of these axons to the perikarya was not seen in the material studied by ultrastructure. Intra-axonal corpora amylacea were often seen in the thoracic nucleus but were not found in conjunction with the axonal enlargements. Myelin sheaths were not generally found about the distended axons although examples were seen. The intra-axonal filaments appeared normal in size and structure, apart from their aberrant arrangement. Unequivocal neuronal perikaryon degeneration or chromatolysis was not found in this ultrastructural study material, and other features of anterior horn degeneration in ALS (such as intraneuronal inclusion bodies or neuronophagia) were not found in this location.

With light microscopy the enlargements were readily found although relatively infrequent in comparison to the anterior horn region. In the latter location one occasionally found fields of axonal masses nearly as large as Clarke's nucleus on section; in the present material an axonal enlargement could be found per one to two spinal cord sections approximately, with unremarkable variation noted between cases. In certain examples (Figure 2), the proximal (to the perikaryon) location of the axonal enlargement could be discerned. The cerebella were not available for study and therefore the presence or absence of distal degeneration was not examined.

\section{DISCUSSION}

Axonal bodies in motor neuron disease were described by Wohlfart (1957) in ventral horns, brainstem and cerebral cortex, and proximal axonal enlargements were emphasized by Carpenter (1968) who illustrated the ultrastructure of the filamentous masses and noted the interesting possibility of analogy with the experimental changes produced by iminodiproprionitrile, which Chou and Hartmann (1965) had described and proposed axoplasmic stasis as a mechanism. Asbury and Johnson (1978) have 
TABLE I

\begin{tabular}{ccccl}
\hline $\begin{array}{c}\text { Patient } \\
\text { number }\end{array}$ & Sex & $\begin{array}{c}\text { Age at } \\
\text { death }\end{array}$ & $\begin{array}{c}\text { Duration of } \\
\text { illness }\end{array}$ & \multicolumn{1}{c}{ Cause of death } \\
\hline I & M & 67 & 11 mos. & pulmonary embolism \\
2 & F & 75 & 2 rrs. & uncertain \\
3 & M & 59 & 2 yrs. & bronchopneumonia \\
4 & F & 82 & 9 mos. & bronchopneumonia \\
5 & M & 64 & 2.5 yrs. & uncertain \\
6 & M & 47 & 1.7 yrs. & carcinoma of bronchus \\
\hline
\end{tabular}

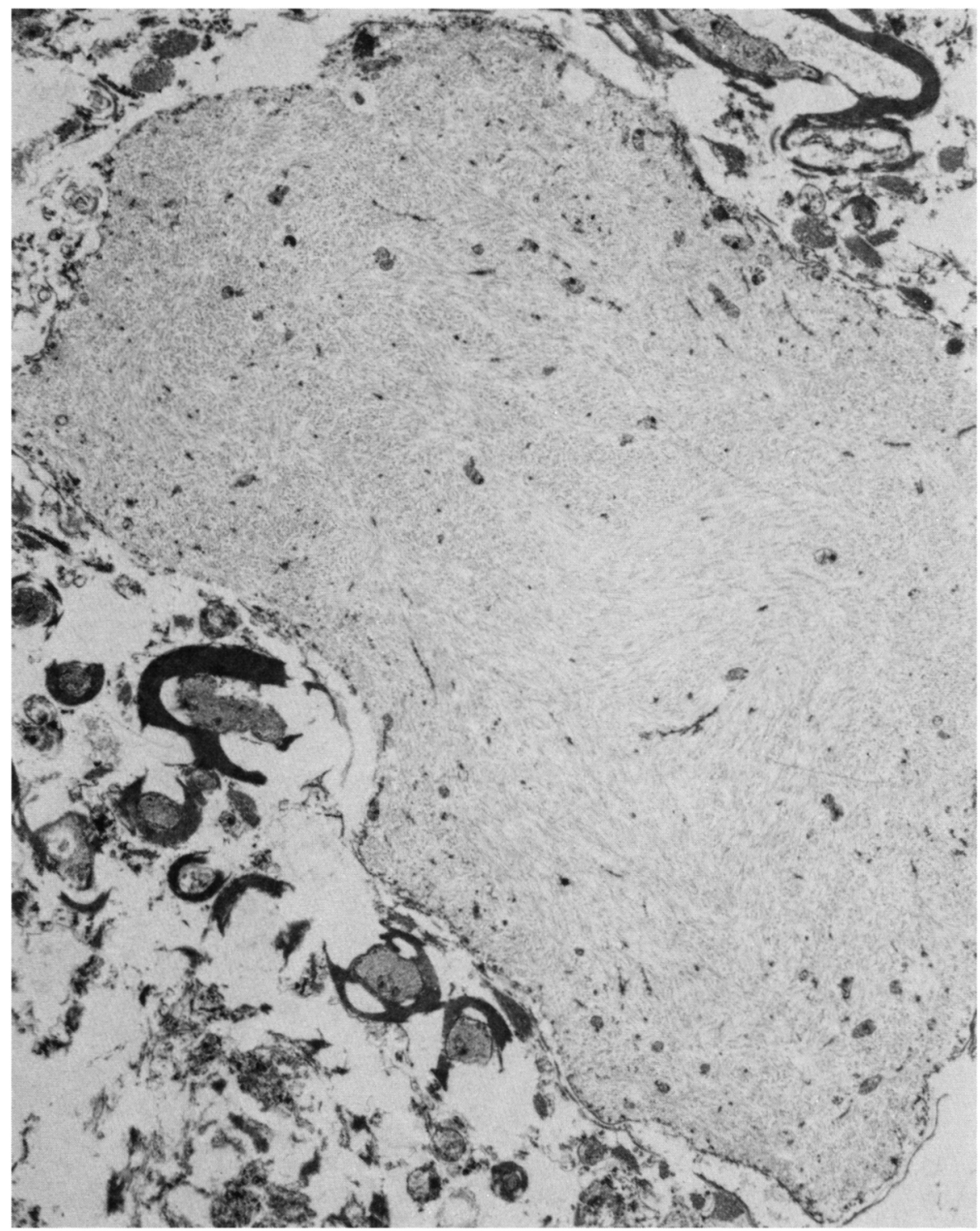

Figure 1 - Enlarged axon in Clarke's nucleus, showing masses of neurofilaments. This structure is in the size range of a neuronal perikaryon. $x 5500$, uranyl acetate and lead citrate. suggested the possible sequence of axostasis due to obstruction of axoplasmic flow by neurofilamentous masses and/or corpora amylacea leading to chromatolysis with lysosomal and other accumulations of neurofilamentous materials in the perikaryon. Intra-axonal corpora amylacea are commonly found in normal control spinal cord (Averback and Langevin, 1978) and therefore seem unlikely to be the cause of putative obstruction. Further observations may help to determine whether the filamentous masses are primary or secondary to axoplasmic stasis, and what other factors may be contributory.

Sporadic ALS is generally considered a system disease primarily but not exclusively restricted to the motor neurons. The nucleus dorsalis (Clarke's nucleus) is considered normal in standard histopathological accounts of the pathology of sporadic ALS (Brownell et al., 1970; Hirano et al., 1975; Iwata and Hirano, 1979; Freedman and Freedman, 1950; Lawyer and Netzky, 1953); ultrastructural study of this region in the sporadic disease does not appear to have been commented upon before. Distal spinocerebellar tract degeneration has often been described in sporadic ALS (Holmes, 1909; McMenemey, 1962), and it therefore seems reasonable to suppose that spinocerebellar system lesions (proximal and distal) are common pathological features of sporadic ALS. Involvement of Clarke's columns is usually found in familial ALS (Hirano, 1975).

Motor involvement with weakness dominates the clinical and pathological picture of ALS; however, the less noticeable spinocerebellar lesions may also be significant. The subtler nature of the latter suggests that the changes may be at an earlier stage of evolution, and that their future study might prove useful.

\section{ACKNOWLEDGEMENTS}

The technical assistance of Mrs. F. Eastwood and Mr. G. Gatward and support from the M.R.C. of Canada are gratefully acknowledged.

\section{REFERENCES}

ASBURY, A.K., JOHNSON, P.C. (1978) 

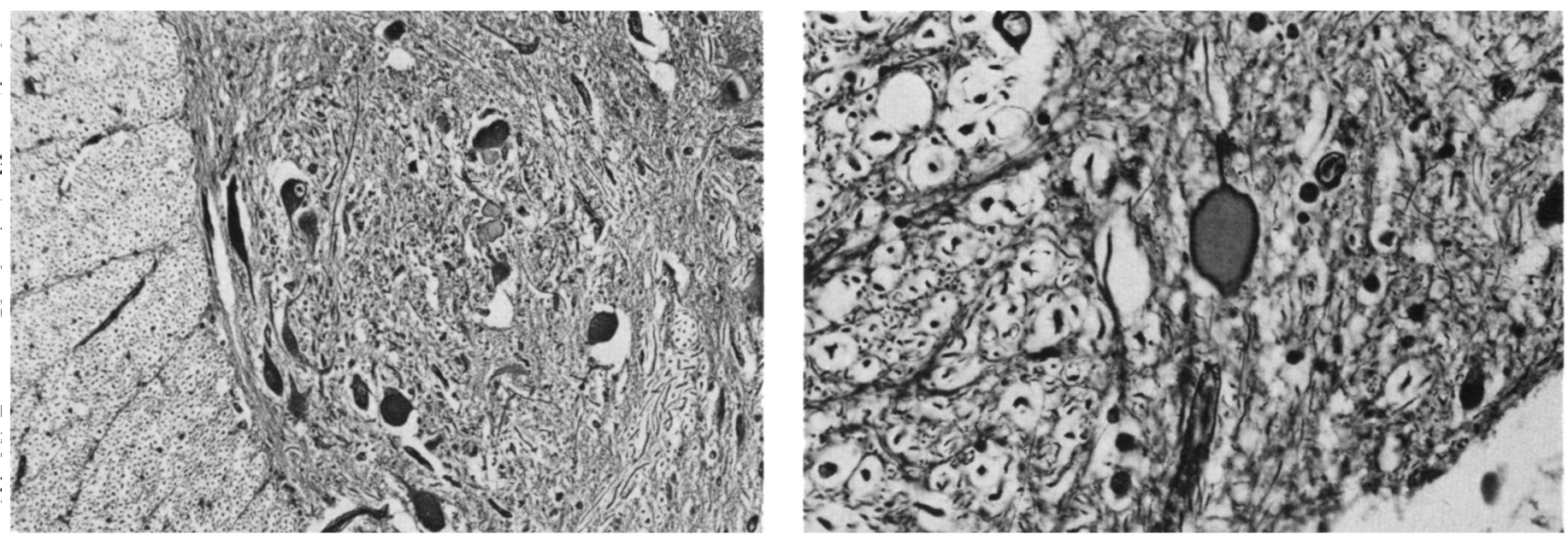

Figure 2 - a) Enlarged axon in Clarke's nucleus, showing proximal location in relation to the neuronal perikaryon. Bodian, $x 250$. b) Enlarged axon in Clarke's nucleus, with dorsal column to left of the field. Bodian, $x 700$.

Pathology of peripheral nerve. Saunders, Philadelphia, p. 252.

AVERBACK, P., LANGEVIN, H. (1978) Corpora amylacea of the lumbar spinal cord and peripheral nervous system. Arch. Neurol. 35, 95-96.

BROWNELL, B., OPPENHEIMER, D.R. and HUGHES. J.T. (1970) The central nervous system in motor neuron disease. $J$. Neurol. Neurosurg. Psychiatry 33, 338.

CARPENTER, S. (1968) Proximal axonal enlargement in motor neuron disease. Neurology 18, 841-851.

CHOU. S.M., and HARTMANN, H.M. (1965) Electron microscopy of focal neuroaxonal lesions produced by $\beta$ - $\beta$-iminodiproprio- nitrile (IDPN) in rats. Acta Neuropath. 4, 590.

FREEDMAN, A.P., and FREEDMAN, D.A. (1950). Amyotrophic lateral sclerosis. J. Nerv. Ment. Dis. 111.1

HIRANO, A. (1975) Progress in the pathology of motor neuron diseases. Progr. Neuropath. (ed. Zimmerman, H.). Grune \& Stratton. New York, 3, 181-215.

HOLMES, G. (1909) The pathology of amyotrophic lateral sclerosis. Rev. Neurol. Psychiat. 7. 693-725.

IWATA, M. and HIRANO, A. (1979) Current problems in the pathology of amyotrophic lateral sclerosis. Progr. Neuropath. (ed. Zimmerman, H.), Grune \& Stratton, New
York, 4, 277-298.

LAWYER, T. JR., and NETZKY, M.G. (1953) Amyotrophic lateral sclerosis: A clinicoanatomical study of 53 cases. Arch. Neurol. Psychiatry (Chicago) 69, 171.

McMENEMEY. W.H. (1962) Discussion on motor neuron disease: pathological aspects. Proc. Roy. Soc. Med. 55, 1021.

WOHLFART, G. (1959) Degenerative and regenerative axonal changes in the ventral horns, brainstem and cerebral cortex in a myotrophic lateral sclerosis. Acta Universitat is Lundensis 56. 1. 